\title{
An In Vitro Cell Culture Model for Pyoverdine-Mediated Virulence
}

\author{
Donghoon Kang (D) and Natalia V. Kirienko *(D) \\ Department of BioSciences, Rice University, Houston, TX 77005, USA; dk30@rice.edu \\ * Correspondence: kirienko@rice.edu
}

\begin{abstract}
Pseudomonas aeruginosa is a multidrug-resistant, opportunistic pathogen that utilizes a wide-range of virulence factors to cause acute, life-threatening infections in immunocompromised patients, especially those in intensive care units. It also causes debilitating chronic infections that shorten lives and worsen the quality of life for cystic fibrosis patients. One of the key virulence factors in P. aeruginosa is the siderophore pyoverdine, which provides the pathogen with iron during infection, regulates the production of secreted toxins, and disrupts host iron and mitochondrial homeostasis. These roles have been characterized in model organisms such as Caenorhabditis elegans and mice. However, an intermediary system, using cell culture to investigate the activity of this siderophore has been absent. In this report, we describe such a system, using murine macrophages treated with pyoverdine. We demonstrate that pyoverdine-rich filtrates from $P$. aeruginosa exhibit substantial cytotoxicity, and that the inhibition of pyoverdine production (genetic or chemical) is sufficient to mitigate virulence. Furthermore, consistent with previous observations made in C. elegans, pyoverdine translocates into cells and disrupts host mitochondrial homeostasis. Most importantly, we observe a strong correlation between pyoverdine production and virulence in P. aeruginosa clinical isolates, confirming pyoverdine's value as a promising target for therapeutic intervention. This in vitro cell culture model will allow rapid validation of pyoverdine antivirulents in a simple but physiologically relevant manner.
\end{abstract}

Keywords: Pseudomonas aeruginosa; pyoverdine; macrophages; virulence

Citation: Kang, D.; Kirienko, N.V. An In Vitro Cell Culture Model for Pyoverdine-Mediated Virulence. Pathogens 2021, 10, 9. https://dx.doi.org/pathogens10010009

Received: 14 November 2020 Accepted: 22 December 2020 Published: 24 December 2020

Publisher's Note: MDPI stays neutral with regard to jurisdictional claims in published maps and institutional affiliations.

Copyright: (c) 2020 by the authors. Licensee MDPI, Basel, Switzerland. This article is an open access article distributed under the terms and conditions of the Creative Commons Attribution (CC BY) license (https: / / creativecommons.org/ licenses/by/4.0/).

\section{Introduction}

Pseudomonas aeruginosa is a Gram-negative, multidrug-resistant, nosocomial pathogen that frequently causes ventilator-associated pneumonia in intensive care units and chronic lung infections in cystic fibrosis patients [1,2]. This pathogen has a particularly diverse set of virulence determinants that facilitate host infection, including those that enable it to avoid immune recognition (e.g., elastases) [3,4] and obtain nutrients within the host (e.g., siderophores, proteases, lipases, etc.) [5]. It also possesses acute virulence factors that damage host cells or tissues, including the type III secretion system [6], and chronic virulence factors that support pathogen colonization, such as quorum-sensing and biofilm formation [7]. However, certain virulence factors, such as the siderophore pyoverdine, have multifaceted roles in P. aeruginosa pathogenesis, making them promising targets for therapeutic intervention.

As a siderophore, pyoverdine exhibits exceptionally high affinity towards ferric iron and is able to remove the metal from host ferroproteins such as transferrin and lactoferrin [8]. Under physiological conditions, where the host actively restricts iron availability, pyoverdine production is necessary for P. aeruginosa iron uptake and growth [9-11]. Pyoverdine production also promotes $P$. aeruginosa biofilm formation [12], which is consistent with the established paradigm that iron availability is necessary for biofilm development [12,13].

Pyoverdine also regulates the expression of secreted toxins in P. aeruginosa. Recognition of ferripyoverdine by its outer membrane receptor, FpvA, releases the sequestration of the 
alternate sigma factor PvdS, allowing it to upregulate genes responsible for the production of the translational inhibitor exotoxin A, the protease PrpL, and pyoverdine itself [14-16]. Exotoxin A in particular has been recognized as one of the most potent toxins secreted by P. aeruginosa, as it can induce apoptotic death in host cells and kill model organisms [17-19]. PrpL (also known as protease IV) is an extracellular protease that degrades host factors necessary for pulmonary mucosal immunity, such as surfactant proteins and interleukin22 [20-22].

We have demonstrated that pyoverdine exerts virulence against the model nematode Caenorhabditis elegans even in the absence of the pathogen [23]. Pyoverdine translocated from the intestinal lumen into host tissue, disrupting iron and mitochondrial homeostasis $[24,25]$. Pyoverdine also inhibited redox metabolism and ATP synthesis, and activated mitochondrial quality control pathways $[24,26,27]$. Some combination of these functions makes pyoverdine critical for $P$. aeruginosa virulence in invertebrate hosts (such as C. elegans and Galleria mellonella) [23,28] and in murine infection [5,10,29].

Several antivirulence strategies have been developed to mitigate pyoverdine-mediated virulence. Notably, 5-fluorocytosine (5-FC), an inhibitor of pyoverdine biosynthesis, attenuates $P$. aeruginosa pathogenesis in C. elegans and mice [30-33]. Other fluoropyrimidines, including 5-fluorouridine (5-FUR) and 5-fluorouracil (5-FU), also have this ability; likely all of them function through the common metabolic intermediate 5-FUR [30]. Other agents that have proven to limit pyoverdine production include twin-arginine translocase inhibitors [34-36], quorum-sensing inhibitors [37-39], and biofilm inhibitors [40]. Pyoverdine-mediated virulence can also be attenuated by gallium (III) nitrate. Gallium has a nearly identical ionic radius to iron and is bound by pyoverdine almost as strongly as iron (III) [41]. However, because gallium (III) is redox inactive, it cannot be removed from the siderophore, causing it to function as a suicide inhibitor. For this reason, gallium (III) rescues G. mellonella or C. elegans from P. aeruginosa pathogenesis [31,42]. We also recently reported several molecules that block pyoverdine function by interacting with the chromophore region of the siderophore $[43,44]$. These inhibitors decreased the expression of PvdS-regulated genes and rescued C. elegans from P. aeruginosa pathogenesis. However, most of these treatments have yet to be validated in mammalian models, partly due to a relative paucity of accessible systems for testing.

In this report, we introduce a robust, in vitro cell culture model where murine macrophage cytotoxicity is associated with exposure to pyoverdine. We demonstrate that spent growth media, which is rich in pyoverdine, exhibits substantial toxicity against cells. Genetic or chemical inhibition of pyoverdine production is sufficient to mitigate this effect. We also demonstrate that pyoverdine translocates into macrophages and disrupts mitochondrial homeostasis, consistent with our previous observations in C. elegans. Importantly, pyoverdine-mediated virulence was observed not only for laboratory-adapted strains of $P$. aeruginosa, but also in clinical isolates from cystic fibrosis patients, where pyoverdine production strongly correlated with cytotoxicity. This model allows rapid virulence assessment and is amenable to high-throughput applications. In addition, this approach will facilitate investigation of the molecular functions of pyoverdine at the mechanistic level in a more biomedically-relevant context.

\section{Results}

\subsection{Pyoverdine Production Is Important for P. aeruginosa Virulence against Murine Macrophages}

To investigate whether pyoverdine production contributes to pathogen virulence in an in vitro cell culture model, we grew P. aeruginosa PAO1 in serum-free cell culture media (Eagle's Minimal Essential Medium, EMEM). As anticipated from the low iron content of this media, $P$. aeruginosa produced substantial amounts of pyoverdine (Figure $1 \mathrm{~A}, \mathrm{~B})$. The levels were comparable to those seen from P. aeruginosa grown in low-iron bacterial media conditions that are commonly used for pyoverdine production (Figure S1). Importantly, an isogenic mutant deficient in pyoverdine production (PAO1 $\Delta p v d F)$ grew to a similar optical density in EMEM, despite producing virtually no detectable pyoverdine. 

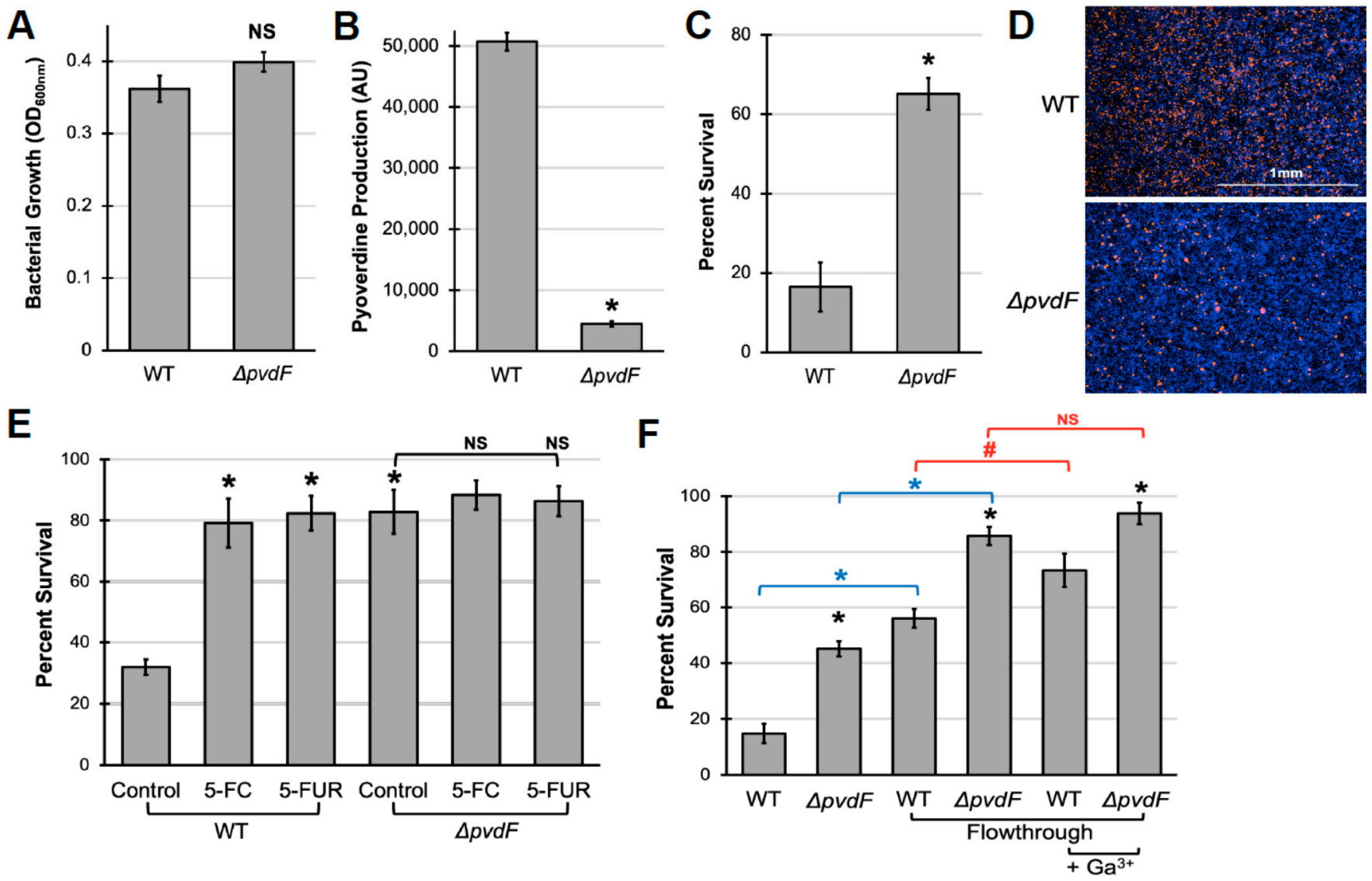

Figure 1. Pyoverdine production is important for virulence in murine macrophages. (A,B) Bacterial growth (A) and pyoverdine production (B) of wild-type P. aeruginosa PAO1 or the pyoverdine biosynthetic mutant PAO1 $\Delta p v d F$ after $16 \mathrm{~h}$ incubation in Eagle's Minimal Essential Medium. (C) RAW264.7 murine macrophage viability after $1.5 \mathrm{~h}$ exposure to filtrates from wild-type PAO1 or PAO1 $\Delta p v d F$. Cell viability was measured using an alamarBlue assay. (D) Visualization of macrophage cell death following filtrate exposure using counterstaining with Sytox Orange, a cell-impermeant nucleic acid stain (red). Cells were prelabeled with Hoechst 33342 (blue) then treated with filtrate in the presence of Sytox Orange for $1 \mathrm{~h}$. (E) Macrophage viability after $1.5 \mathrm{~h}$ exposure to filtrates from bacteria grown in the presence of $50 \mu \mathrm{M} 5$-fluorocytosine (5-FC) or $10 \mu \mathrm{M}$ 5-fluorouridine (5-FUR). (F) Macrophage viability after $2.5 \mathrm{~h}$ exposure to bacterial filtrates from wild-type $\mathrm{PAO} 1$ or PAO1 $\triangle p v d F$ before and after the removal of large biomolecules by centrifugal filtration $(<5 \mathrm{kDa}$ flowthrough) or after pre-saturating the pyoverdine in the flowthrough with $250 \mu \mathrm{M}$ gallium (III) nitrate. Error bars represent SEM from at least three biological replicates. * corresponds to $p<0.01$, \# corresponds to $p<0.05$, and NS corresponds to $p>0.05$ based on Student's $t$-test.

RAW264.7 murine macrophages were exposed to spent, cell-free media (hereafter referred to as "filtrate", see Section 4 for details) from wild-type and pyoverdine-deficient $P$. aeruginosa cultures to examine these materials' ability to kill mammalian cells. Macrophages treated with wild-type filtrate showed substantial cell death, as measured using the alamarBlue cell viability assay, while cells treated with pyoverdine-deficient filtrate had significantly better survival (Figure 1C). We validated these results using another cell viability assay that uses a combination of cell-permeable (Hoechst 33342) and cell-impermeable (Sytox Orange) dyes to identify living and dead cells (Figure 1D), indicating that pyoverdine production is associated with cytotoxicity in macrophages. We observed similar results in two other murine macrophage cell lines, J774A.1 and the alveolar macrophage cell line MH-S (Figure S2).

Importantly, filtrate toxicity was independent of pyochelin, another major siderophore produced by P. aeruginosa. The pyochelin biosynthetic mutant (PAO1 $\triangle p c h B A)$ did not exhibit significant differences in bacterial growth, pyoverdine production, or filtrate toxicity from that of wild-type bacteria (Figure S3). Interestingly, disruption of pyochelin 
production in the pyoverdine mutant was sufficient to deprive the pathogen of iron, inhibiting bacterial growth, and attenuating virulence. Furthermore, although pyocyanin, a toxin known to induce oxidative stress in host cells $[45,46]$, was present in filtrates at concentrations of $4.3 \pm 0.6 \mu \mathrm{M}$, it was insufficient to induce macrophage death within the timeframe of pyoverdine-mediated damage, as demonstrated with purified pyochelin (Figure S4).

We further validated our in vitro pathogenesis model by treating macrophages with bacterial filtrates from $P$. aeruginosa grown in the presence of the pyoverdine biosynthetic inhibitors 5-fluorocytosine (5-FC) or 5-fluorouridine (5-FUR), which were added prior to inoculation $[30,32]$. Under our growth conditions, these drugs effectively inhibited pyoverdine production without overtly affecting bacterial growth (Figure S5). Inhibition of pyoverdine production by these compounds attenuated filtrate toxicity for wild-type P. aeruginosa (Figure 1E). Fluoropyrimidines had no apparent effect on cell viability for macrophages treated with filtrate from the biosynthetic mutant. This is consistent with our previous observations that the mitigation of virulence by these fluoropyrimidines functions solely by limiting pyoverdine production [30].

In a previous study, we demonstrated that pyoverdine directly exerts virulence against C. elegans by treating hosts with bacterial filtrates that had been autoclaved to inactivate heat-labile materials, which includes most proteins. However, this treatment could have damaged other molecules as well. To rule out the possibility that other molecules were responsible for the cytotoxicity seen in macrophages, filtrates were passed through a $5 \mathrm{kDa}$ centrifugal filter to remove large macromolecules. Pyoverdine produced by P. aeruginosa PAO1, often referred to as Type I pyoverdine, has a molecular weight of approximately $1,350 \mathrm{Da}$. As expected, pyoverdine passed through the membrane with relative ease; $75 \%$ of the initial pyoverdine was found in this low-molecular-weight fraction (hereafter referred to as "flowthrough") as judged by fluorescence (Figure S6). Cell viability was measured in macrophages that were exposed to this low-molecular-weight material from wild-type $P$. aeruginosa or the pyoverdine biosynthetic mutant. As expected, the flowthrough from wild-type bacteria had greater cytotoxicity, although removing large macromolecules reduced cell death for both genotypes (Figure 1F). We hypothesized that the difference in the ability of flowthrough from wild-type and pyoverdine mutant to kill macrophages is likely due to direct cytotoxicity from pyoverdine (i.e., it is independent of proteinaceous virulence factors upregulated by pyoverdine). Consistent with this hypothesis, pre-incubation of the flowthrough with equimolar concentrations of gallium (III) nitrate reduced the cytotoxicity of wild-type material by $40 \%$ (Figure 1F). However, even in the presence of gallium, there was considerable difference between the cells treated with wild-type and pyoverdine mutant flowthrough, suggesting that pyoverdine is not the only factor contributing to cell death.

\subsection{Pyoverdine Translocates into Macrophages and Disrupts Mitochondrial Function}

The likeliest explanation for the cell death we observed is that pyoverdine is interacting with the cellular iron pool. Depletion of iron from the medium is unlikely to cause these levels of cell death in the time frame examined. In order to have this effect, though, pyoverdine would first need to gain entry into cells. To determine whether pyoverdine was within cells, macrophages were treated with flowthrough for $2 \mathrm{~h}$ and then washed to remove extracellular pyoverdine. Cells were then lysed in the presence of excess 8hydroxyquinoline (8HQ). Excess $8 \mathrm{HQ}$ strips iron from pyoverdine, restoring pyoverdine fluorescence that had been quenched by iron-binding before or during cell lysis [47]. We observed substantial pyoverdine fluorescence in macrophage cell lysates treated with the flowthrough from wild-type $P$. aeruginosa but not in cells treated with material from the pyoverdine mutant (Figure 2A). This fluorescence was quenched by the addition of ferric iron, indicating that it originated from pyoverdine. 
A

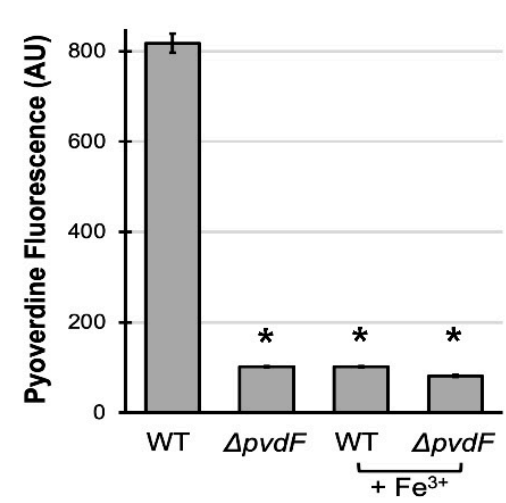

B

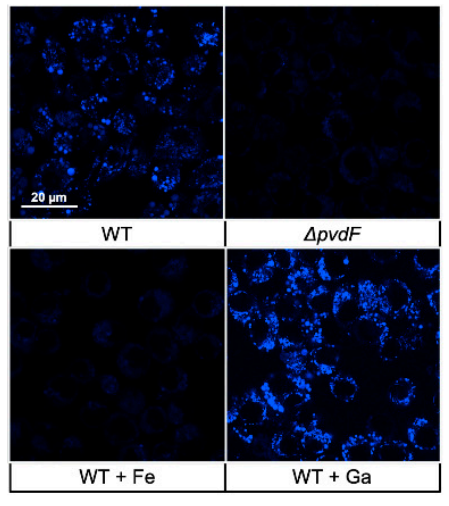

C

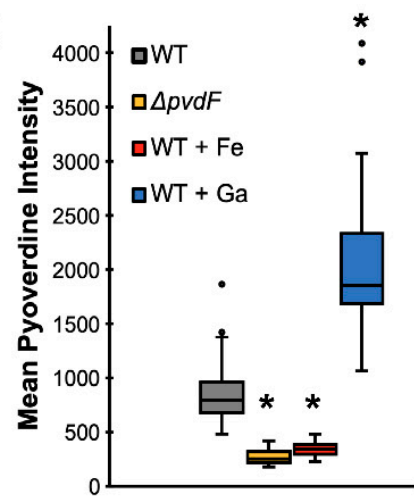

D

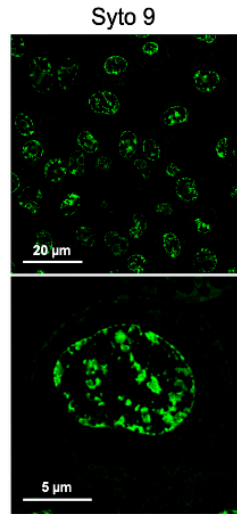

Pyoverdine - Ga

CellMask Deep Red

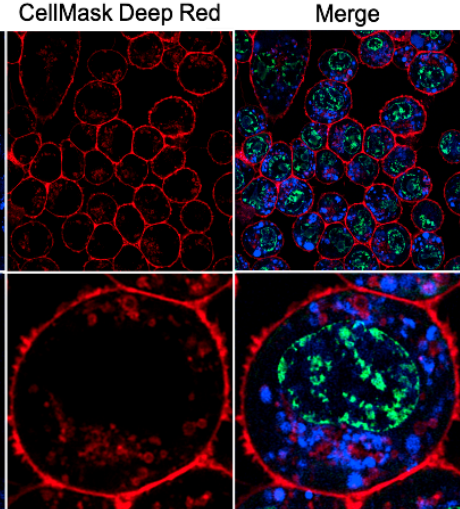

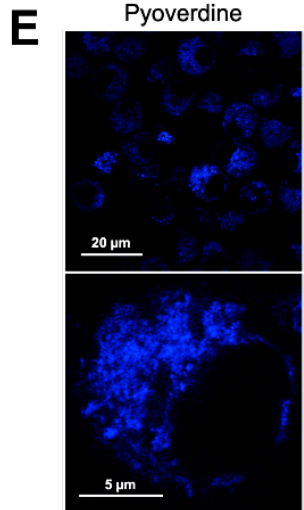

Dextran TR

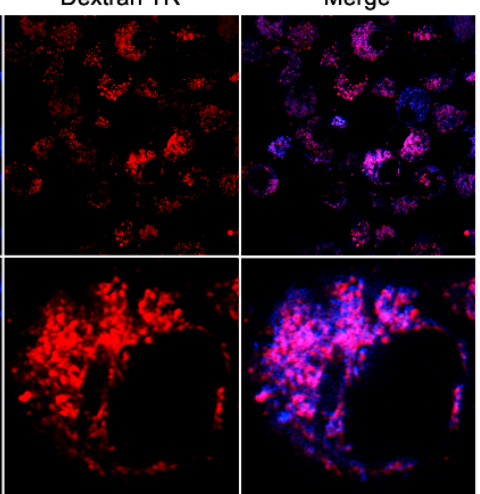

Figure 2. Pyoverdine translocates into macrophages. (A) Pyoverdine fluorescence in macrophage cell lysates after $2 \mathrm{~h}$ exposure to low-molecular weight flowthrough from bacterial filtrates. Lysate fluorescence was quenched by exogenous ferric iron. (B) Pyoverdine fluorescence within macrophages visualized via confocal laser-scanning microscopy after $1.5 \mathrm{~h}$ exposure to flowthrough pretreated with iron (III) chloride, gallium (III) nitrate, or solvent control. (C) Quantification of pyoverdine fluorescence within 50 individual cells. (D) Pyoverdine-gallium fluorescence within cells labeled with Syto 9 green fluorescent nucleic acid stain and CellMask deep red plasma membrane stain. The bottom row shows an enlarged micrograph of one representative cell. (E) Pyoverdine and dextran fluorescence within macrophages were visualized after $1.5 \mathrm{~h}$ exposure to wild-type flowthrough supplemented with dextran-Texas Red (10,000 MW). The bottom row shows an enlarged micrograph of one representative cell. Error bars in (A) represent SEM from three biological replicates. * corresponds to $p<0.01$ based on Student's t-test. Cells labeled with Syto 9, CellMask, or dextran in the absence of pyoverdine are shown in Figure S7.

We also visualized pyoverdine's innate fluorescence within cells using confocal microscopy. Macrophages exposed to flowthrough from wild-type bacteria accumulated substantial intracellular pyoverdine (Figure 2B, upper left). In contrast, cells treated with material from pyoverdine-deficient mutants (Figure 2B, upper right, Figure 2C) or filtrate quenched with ferric iron (Figure 2B, lower left, Figure 2C) showed no fluorescence in the channel characteristic for pyoverdine. Chelating gallium (III) is known to considerably increase the quantum yield of pyoverdine [48]. As anticipated, pre-incubating pyoverdine with gallium (III) increased the fluorescence yield of cells treated with wild-type, but not pyoverdine-deficient material (Figure 2B, lower right, Figure 2C, Figure S7A,B). This difference in fluorescence between samples treated with pyoverdine and pyoverdine with gallium may also be partly explained by the quenching of pyoverdine fluorescence upon the chelation of intracellular iron. In either case, gallium chelation did not diminish the ability of the siderophore to translocate into mammalian cells.

To rule out the possibility that the fluorescence observed was due to accumulation of pyoverdine on the cell surface, we counterstained the plasma membrane and nucleus in macrophages treated with the pyoverdine-gallium complex. The increased fluorescence yield allowed us to visualize pyoverdine, despite its partial overlap in emission spectra with that of the nucleic acid counterstain. Pyoverdine fluorescence was also distinct from 
that of the plasma membrane (Figure 2D), indicating that pyoverdine is localized to a subcellular compartment, perhaps a sorting compartment like the early endosome.

We tested this localization by exposing macrophages to both pyoverdine and Texas Red-labeled dextran (10,000 MW), which macrophages internalize via macropinocytosis. Dextran of this molecular weight range is well-established as a tool for visualizing early endosomes [49]. We observed extensive colocalization of pyoverdine and dextran (Figure 2E), indicating that most of the pyoverdine was likely in this cellular compartment. However, we did see some areas that only had pyoverdine fluorescence, which may indicate that the siderophore is also present elsewhere in the cell.

Based on its translocation into cells and its exceptionally high affinity for iron (higher than most host ferroproteins), we hypothesized that pyoverdine was likely to be hijacking host iron. One expected consequence of this activity is the disruption of mitochondrial function such as the fragmentation of mitochondrial networks which can be visualized using MitoTracker Green FM dye. For instance, cells treated with the mitochondrial uncoupler carbonyl cyanide 3-chlorophenylhydrazone (CCCP) exhibit such fragmentation (Figure 3A). We treated macrophages with flowthrough from wild-type PAO1 or the $\triangle p v d F$ mutant and evaluated the effects of pyoverdine on host mitochondrial networks. Mitochondrial networks in macrophages treated with wild-type flowthrough exhibited substantially greater fragmentation compared to those in cells treated with material from the pyoverdine biosynthetic mutant (Figure 3B). These findings are consistent with our previous results where pyoverdine disrupts C. elegans mitochondrial homeostasis [24,25].
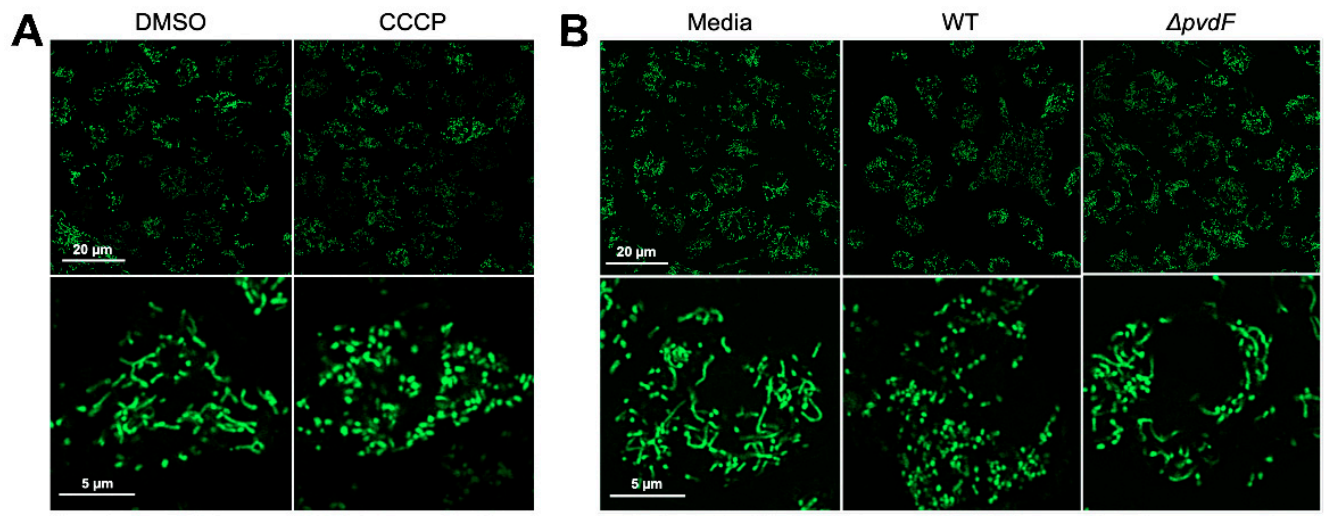

Figure 3. Pyoverdine production disrupts host mitochondrial networks. (A) Visualization of mitochondrial morphology in murine macrophages via MitoTracker Green FM staining after $2.5 \mathrm{~h}$ exposure to $50 \mu \mathrm{M}$ CCCP or DMSO solvent control. (B) MitoTracker Green FM staining in macrophages after $1 \mathrm{~h}$ exposure to flowthrough. Bottom row shows enlarged micrograph of a representative cell.

\subsection{Pyoverdine Production Correlates to Virulence in P. aeruginosa Clinical Isolates}

Finally, we investigated the role of pyoverdine production in the virulence of $P$. aeruginosa isolates obtained from patients with cystic fibrosis. Previously, we compared the virulence of strains that exhibited high (PA2-61, PA2-72) or low (PA2-88, PA3-22) levels of pyoverdine production in C. elegans [31]. For comparison, we tested the amount of pyoverdine produced by these strains in Liquid Killing (LK) media and in serum-free EMEM (Figure 4A,B). Exposure to the high-pyoverdine producing strains PA2-61 or PA2-72 was much more lethal to C. elegans in the Liquid Killing assay than to their low-pyoverdine producing counterparts, PA2-88 or PA3-22 (Figure 4C). A similar pattern was seen in macrophages. Bacterial filtrates from PA2-61 and PA2-72 were more toxic to macrophages than identically-prepared materials from PA2-88 and PA3-22, which caused virtually no cytotoxicity (Figure 4D). As we observed for PAO1, 5-FC inhibited pyoverdine production in the two virulent isolates, attenuating filtrate cytotoxicity (Figure 4D). 

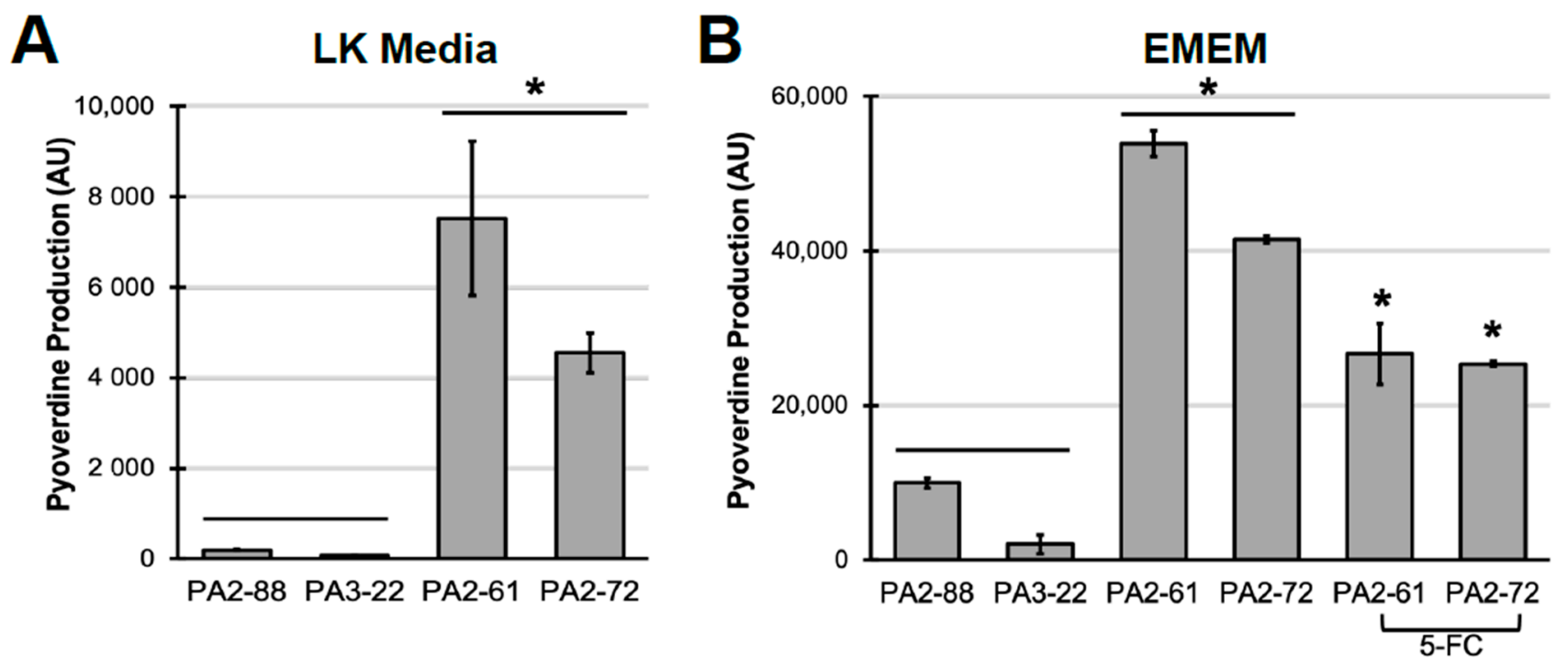

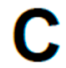

C. elegans

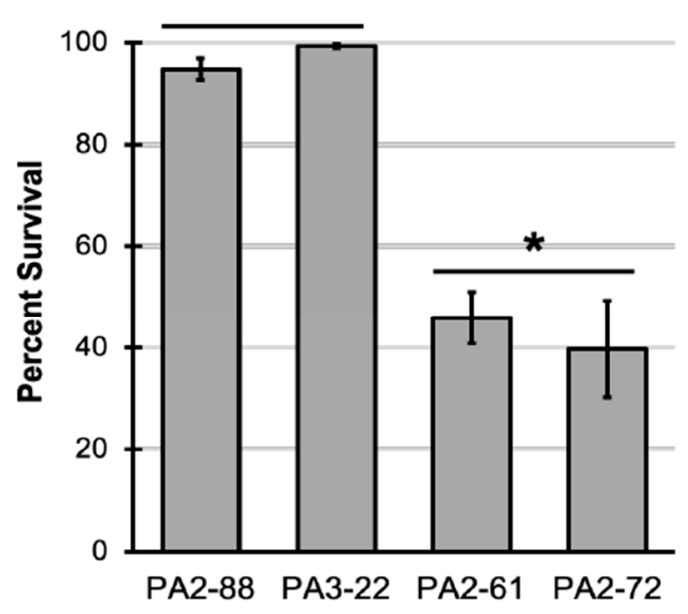

D

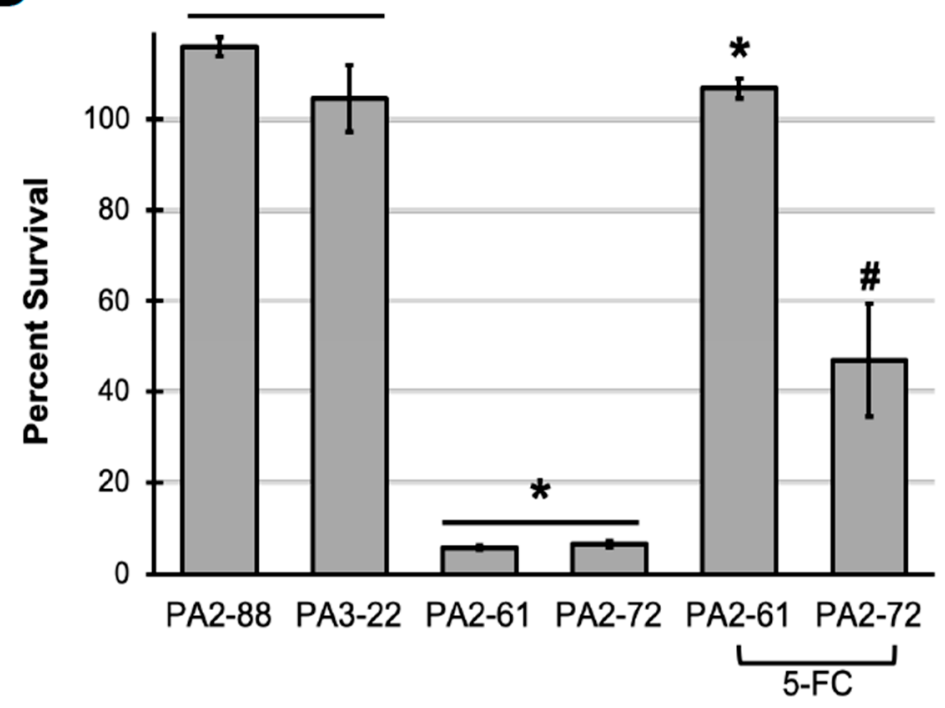

Figure 4. In vitro macrophage pathogenesis model recapitulates results from C. elegans. (A) Pyoverdine production by P. aeruginosa cystic fibrosis isolates after growth in Liquid Killing media in the presence of C. elegans. (B) Pyoverdine production by P. aeruginosa cystic fibrosis isolates in Eagle's Minimum Essential Medium with or without $50 \mu \mathrm{M} 5$ fluorocytosine (5-FC). (C) C. elegans survival after exposure to P. aeruginosa under Liquid Killing conditions. (D) Macrophage survival after exposure to bacterial filtrates from P. aeruginosa. Error bars represent SEM from three biological replicates. * corresponds to $p<0.01$ and \# corresponds to $p<0.05$ based on Student's $t$-test.

To more broadly explore the relationship between pyoverdine and virulence, we expanded our survey to include 19 additional $P$. aeruginosa isolates from various sources, including burn wounds, urinary tract infections, and plants [50]. These isolates displayed heterogeneity with regard to pyoverdine production, though most strains exhibited significant levels of pyoverdine (at least $30 \%$ of that of PAO1, Figure 5A). As expected, we observed a strong correlation between pyoverdine levels and filtrate cytotoxicity (Figure 5B). Importantly, this correlation was not due to differences in bacterial growth (Figure 5C,D). These results reaffirm the role of pyoverdine in our in vitro macrophage pathogenesis model and indicate that pyoverdine may be a useful target for clinical intervention. 

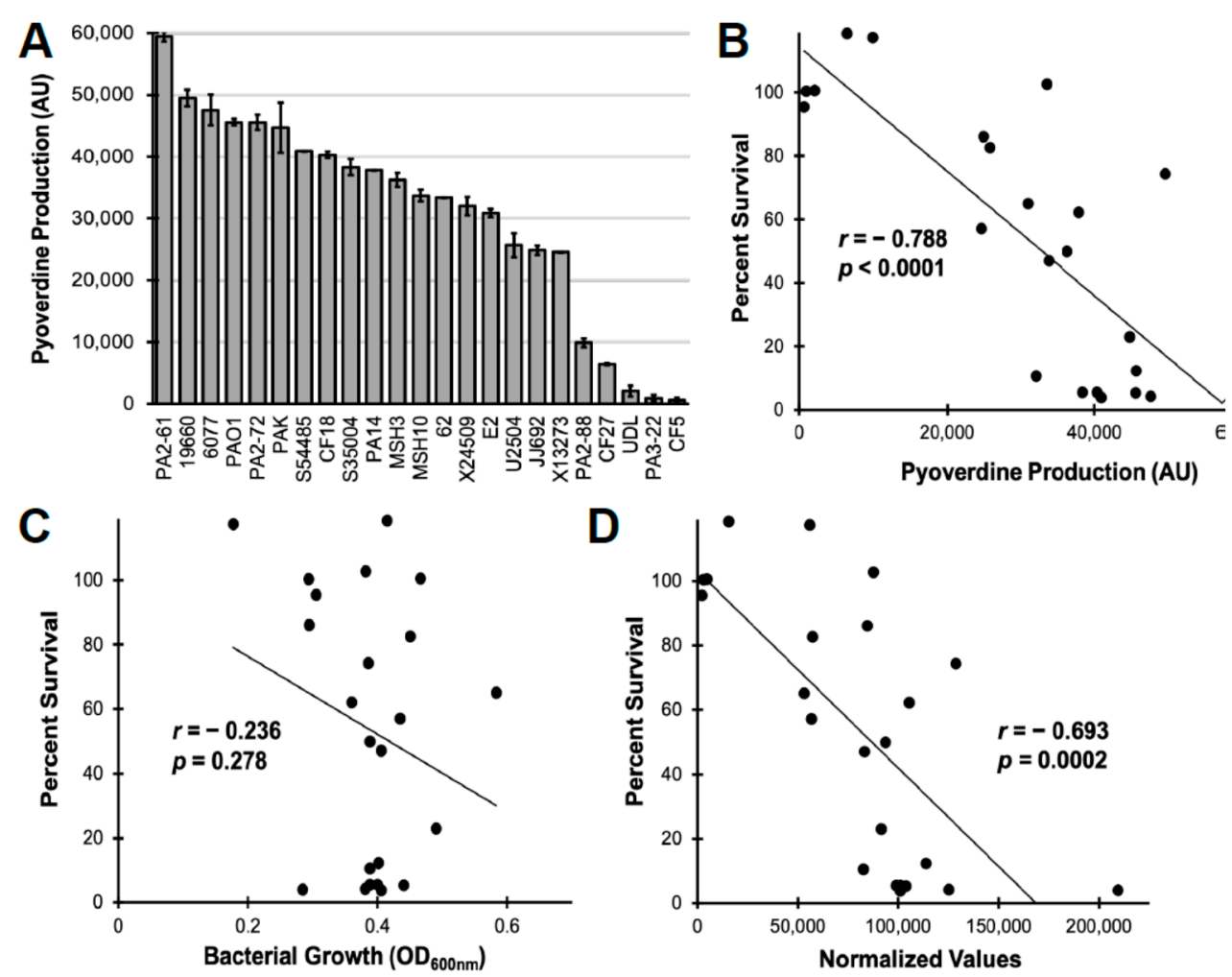

Figure 5. Pyoverdine production correlates with pathogen virulence in P. aeruginosa clinical and environmental isolates. (A) Pyoverdine production by a panel of 23 P. aerugionosa isolates after $16 \mathrm{~h}$ incubation in serum-free Eagle's Minimum Essential Medium. (B-D) Correlation between pyoverdine production (B), bacterial growth (C), or pyoverdine normalized to growth (D) and filtrate toxicity against murine macrophages. Error bars represent SEM from two biological replicates. Each point represents the average of two biological replicates.

\section{Discussion}

In response to the rising prevalence of bacterial drug resistance, increased interest has been shown in the investigation of alternative treatment approaches, including inhibiting bacterial virulence. Compounds with this function generally prevent either the biosynthesis, the secretion, or the function of their target. Importantly, antivirulents are likely to fall into two different categories: pure antivirulents, which do not overtly compromise pathogen growth or survival, and mixed-function compounds, which may inhibit both virulence and bacterial growth by either the same or different mechanisms. It is postulated that the reduced effect on bacterial growth by pure antivirulents might limit the selective pressure on pathogens to develop resistance, which could extend the long-term utility of these drugs.

Model organisms, including C. elegans, mammalian cells, and mice have facilitated the development of P. aeruginosa antivirulents. Work in mice and C. elegans has established an important role for pyoverdine in virulence $[5,23,31,51]$, and validated antivirulents that were identified in various biochemical screens. For instance, Imperi and colleagues identified 5-fluorocytosine from a screen for pyoverdine biosynthetic inhibitors and validated its therapeutic properties in a murine lung infection model [32]. Our lab has identified several compounds that inhibit pyoverdine function and rescue $C$. elegans hosts during P. aeruginosa pathogenesis [43]. Inhibitors of the type III secretion system, elastase LasB, and quorum-sensing have also been identified and validated using these model pathosystems [52-55].

Due to their inexpensive maintenance conditions, rapid generation time, and small size, C. elegans has been a robust tool for the development of high-content, high-throughput screens for host-pathogen interactions. For instance, we performed a screen to identify molecules that rescue $C$. elegans during $P$. aeruginosa Liquid Killing and identified pyoverdine biosynthetic inhibitors such as fluoropyrimidines and inhibitors of pyoverdine 
function. C. elegans-based platforms have also been used to discover novel anti-infectives against Enterococcus faecalis, Staphylococcus aureus, and Candida albicans [56-58]. However, while $C$. elegans are amenable to high-throughput screens, they will not completely recapitulate host-pathogen interactions seen in mammalian hosts. Notably, C. elegans are immune to P. aeruginosa type III secretion [59], one of the most important acute virulence factors in the pathogen [6].

While validation of anti-infectives using murine-infection models is the best approach, it is also expensive and comes with an ethical burden. It may also be impractical to test a large number of therapeutic leads. Establishing intermediary pathogenesis assays, such as monolayer or three-dimensional cell culture models $[60,61]$ may prove invaluable for quickly evaluating the therapeutic potential of novel drugs.

Thus far, several in vitro models have been developed for type III secretion-mediated virulence in P. aeruginosa. For instance, early work has established that effectors injected by the type III secretion system, such as ExoT or ExoU, induce apoptotic or necrotic death in mammalian cells, respectively $[62,63]$. In P. aeruginosa macrophage infection models, the pathogen activates the NLRC4/IPAF inflammasome via flagellin and the type III secretion system to induce pyroptosis [64-66]. P. aeruginosa can also activate the NLRP3 inflammasome to mitigate phagocytic killing by macrophages [67]. In endothelial cell infection models, the type III secretion system and the elastase LasB disrupt endothelial cell junction permeability, a key mechanism of bacterial dissemination within the host $[68,69]$. Another potentially useful set of in vivo models for researching $P$. aeruginosa virulence utilizes amoebal species such as Acanthamoeba castellanii and Dictyostelium discoideum [70,71].

To the best of our knowledge, we report here the first model for pyoverdine-mediated virulence in mammalian cell culture. Pyoverdine has been well-established as a key virulence factor in P. aeruginosa. Pyoverdine's ability to provide iron for the pathogen and regulate downstream effectors such as exotoxin A and PrpL has been attributed to bacterial virulence in the mouse lung [5]. While our model differs from more conventional P. aeruginosa infection assays by focusing solely on secreted bacterial factors, we have recapitulated results obtained from C. elegans Liquid Killing and murine lung infection models. Moreover, this in vitro cell culture model provided unique insights into the effects of pyoverdine intoxication. While we previously demonstrated that pyoverdine translocates from the C. elegans intestinal lumen into neighboring tissue, we were unable to definitively prove that pyoverdine was present inside host cells [24]. In contrast, demonstrating internalization in murine macrophages was much simpler, and we were able to determine that pyoverdine is likely to localize to early endosomal compartments and visualize the mitochondrial damage that results from exposure. Future work in this model, and the wealth of cell biological tools available, may help elucidate the interactions between pyoverdine and intracellular iron sources, including mitochondrial ferroproteins. We are currently investigating whether other cell lines, including lung epithelial cells, also show pyoverdinedependent cytotoxicity to more easily understand the effects of pyoverdine in the context of cystic fibrosis or ventilator-associated pneumonia.

\section{Materials and Methods}

\subsection{Bacterial Strains and Growth Conditions}

P. aeruginosa PAO1 and pyoverdine biosynthetic mutant PAO1 $\Delta p v d F$ were provided by Dr. Dieter Haas. P. aeruginosa cystic fibrosis isolates PA2-88, PA3-22, PA2-61, and PA2-72 were provided by Dr. Carolyn Cannon [31]. The remaining clinical and environmental isolates in Figure 5 were provided by Dr. Frederick Ausubel [50].

To generate pyoverdine-rich, spent bacterial cultures, called "filtrates" herein, P. aeruginosa overnight culture grown in LB medium was diluted 20-fold into $2 \mathrm{~mL}$ of Eagle's Minimum Essential Medium (EMEM) (Millipore Sigma, Burlington, MA, USA) in 6-well plates. The plate was covered with an air-permeable membrane and bacteria were grown statically at $37^{\circ} \mathrm{C}$ for $16 \mathrm{~h}$. Bacteria were then pelleted, and the supernatant was filtered through a $0.22 \mu \mathrm{m}$ membrane. The filtrate was treated with $150 \mu \mathrm{g} / \mathrm{mL}$ amikacin to kill any 
remaining bacteria. To remove large biomolecules, this material was then filtered through a Vivaspin 5000 MWCO PES membrane centrifugal concentrator (Sartorius, Gottingen, Germany) at 3600 RCF, yielding the material herein referred to as "flowthrough".

To chemically inhibit pyoverdine production, EMEM was supplemented with $50 \mu \mathrm{M}$ 5-fluorocytosine (5-FC) or $10 \mu \mathrm{M}$ 5-fluorouridine (5-FUR) prior to bacterial inoculation.

\subsection{Macrophage Cell Lines and Growth Conditions}

RAW264.7 and J774A.1 murine macrophages and MH-S murine alveolar macrophages were purchased from ATCC (Manassas, VA, USA). All cell lines were grown and passaged in RPMI medium supplemented with $10 \%$ bovine calf serum and penicillin/streptomycin (Millipore Sigma, Burlington, MA, USA) at $37^{\circ} \mathrm{C}$ and $5 \% \mathrm{CO}_{2}$ in a Symphony air-jacketed incubator (VWR, Radnor, PA, USA).

\subsection{Cell Viability Assay}

To perform the alamarBlue cell viability assay, approximately $2 \times 10^{6}$ cells were seeded into each well of a 12-well plate $(1 \mathrm{~mL} /$ well $)$ and grown to $>95 \%$ confluency. The growth medium was then aspirated and replaced with bacterial filtrate. After filtrate exposure, $100 \mu \mathrm{L}$ of alamarBlue HS Cell Viability Reagent (Invitrogen, Carlsbad, CA, USA) was added to each well and cells were incubated for an additional $1 \mathrm{~h}$. The supernatant was then collected and briefly centrifuged to remove cells. Then, $100 \mu \mathrm{L}$ of supernatant was transferred to a 96-well plate and resorufin fluorescence (Ex. $560 \mathrm{~nm} ; \mathrm{Em} .590 \mathrm{~nm}$ ) was measured using a Cytation 5 multimode reader (Biotek, Winooski, VT, USA). Cell viability was calculated as a percentage of fluorescence measured from cells treated with bacterial filtrates compared to media control.

For Hoechst 33342 and Sytox Orange staining, approximately $2 \times 10^{5}$ cells were seeded and adhered onto each well of a 96-well black clear bottom plate (100 $\mu \mathrm{L} /$ well $)$. Cells were then stained with $8 \mu \mathrm{M}$ Hoechst 33342 (Thermo Fisher Scientific, Waltham, MA, USA) in RPMI medium for $30 \mathrm{~min}$. Afterwards, the Hoechst solution was aspirated and replaced with bacterial filtrate supplemented with $2.5 \mu \mathrm{M}$ Sytox Orange (Invitrogen, Carlsbad, CA, USA). After filtrate exposure, cells were gently washed in RPMI medium and imaged using a Cytation5 multimode reader (Biotek, Winooski, VT, USA).

\subsection{Measuring Pyoverdine Content}

To measure pyoverdine production by P. aeruginosa, $100 \mu \mathrm{L}$ of bacterial culture was transferred to a 96-well plate, and pyoverdine fluorescence (Ex. $405 \mathrm{~nm}$; Em. $460 \mathrm{~nm}$ ) was measured using a Cytation5 multimode reader (Biotek, Winooski, VT, USA).

To measure pyoverdine content in macrophages, cells were grown in T25 flasks to $>95 \%$ confluency. The growth medium was then aspirated and replaced with low-molecularweight material from bacterial filtrates. After $2 \mathrm{~h}$ treatment, cells were scraped off, washed in phosphate-buffered saline (PBS) to remove exogenous pyoverdine, and resuspended in PBS. The cell suspension was mixed with $2 \mathrm{M}$ 8-hydroxyquinoline in chloroform at a 1:1 $(\mathrm{v} / \mathrm{v})$ ratio, vortexed for $1 \mathrm{~min}$, and incubated at room temperature for $8 \mathrm{~h}$ on a tube rotator. The mixture was then centrifuged at 16,000 RCF for $5 \mathrm{~min}$. Pyoverdine fluorescence in the aqueous layer was measured using a Cytation5 multimode reader (Biotek, Winooski, VT, USA).

\subsection{Confocal Microscopy}

Approximately $1.25 \times 10^{6}$ cells were seeded and adhered onto each well of a LabTek II 8-well chambered cover glass (Thermo Fisher Scientific, Waltham, MA, USA) (500 $\mu \mathrm{L} /$ well). To visualize pyoverdine fluorescence within macrophages, cells were treated with flowthrough material from bacterial filtrates supplemented with $250 \mu \mathrm{M}$ $\mathrm{FeCl}_{3}, \mathrm{Ga}\left(\mathrm{NO}_{3}\right)_{3}$, or solvent control and washed in RPMI medium to remove excess material. Pyoverdine fluorescence was visualized via a $405 \mathrm{~nm}$ laser-line using channel conditions for Pacific Blue on a Zeiss LSM 800 confocal laser-scanning microscope (Zeiss, 
Oberkochen, Germany). All micrographs were processed using Airyscan 2D SR processing to acquire super-resolution images. Pyoverdine fluorescence in each cell was quantified by its mean fluorescence intensity using ZEN image analysis software.

To label the cell nucleus and plasma membrane, cells were treated with $5 \mu \mathrm{M}$ Syto 9 green fluorescent nucleic acid stain (Invitrogen, Carlsbad, CA, USA) and $5 \mu \mathrm{g} / \mathrm{mL}$ CellMask deep red plasma membrane stain (Invitrogen, Carlsbad, CA, USA) in RPMI medium for $30 \mathrm{~min}$ after pyoverdine exposure. Syto 9 fluorescence was visualized via a $488 \mathrm{~nm}$ laserline using channel conditions for FITC. CellMask fluorescence was visualized via a $640 \mathrm{~nm}$ laser-line using channel conditions for Alexa Fluor 660. To label endocytic compartments, low-molecular-weight filtrate was supplemented with $250 \mu \mathrm{g} / \mathrm{mL}$ dextran Texas Red, 10,000 MW (Invitrogen, Carlsbad, CA, USA). Dextran fluorescence was visualized via a $561 \mathrm{~nm}$ laser-line using channel conditions for Texas Red. All micrographs were processed using Airyscan 2D SR processing to acquire super-resolution images.

To visualize mitochondrial networks, cells were first treated with flowthrough then stained with $500 \mathrm{nM}$ MitoTracker Green FM (Invitrogen, Carlsbad, CA, USA) in RPMI medium for $30 \mathrm{~min}$. Cells were washed in RPMI medium to remove excess dye. MitoTracker Green fluorescence was visualized via a $488 \mathrm{~nm}$ laser-line using the channel conditions for eGFP. All micrographs were processed using Airyscan 2D SR processing to acquire super-resolution images.

\subsection{C. elegans Liquid Killing}

C. elegans Liquid Killing (LK) was performed as previously described [72,73]. In brief, worms were treated with P. aeruginosa in LK media (25\% SK media $(0.3 \% \mathrm{NaCl}, 0.35 \%$ Bacto Peptone in water) in S Basal buffer $(100 \mathrm{mM} \mathrm{NaCl}, 50 \mathrm{mM}$ potassium phosphate, $\mathrm{pH}$ 6.0)) in 384-well plates. After pathogen exposure, worms were stained with Sytox Orange (Invitrogen, Carlsbad, CA, USA) to label dead organisms. Fluorescent images were acquired using a Cytation5 multimode reader (Biotek, Winooski, VT, USA) and analyzed using CellProfiler.

Supplementary Materials: The following are available online at https:/ /www.mdpi.com/2076-081 7/10/1/9/s1. Figure S1: P. aeruginosa produces pyoverdine in serum-free cell culture medium;Figure S2: Pyoverdine production is important for virulence in different murine macrophage cell lines; Figure S3: P. aeruginosa filtrate toxicity is independent of pyochelin production; Figure S4: Pyocyanin does not contribute to filtrate toxicity; Figure S5: Fluoropyrimidines function as pyoverdine antivirulents; Figure S6: Pyoverdine is present in the low-molecular-weight fraction of the filtrate (flowthrough); Figure S7: Intracellular pyoverdine fluorescence is not observed in cells treated with pyoverdinedeficient material.

Author Contributions: Conceptualization, D.K. and N.V.K.; methodology, D.K.; formal analysis, D.K. and N.V.K.; data curation, D.K.; writing—original draft preparation, D.K.; writing-review and editing, D.K. and N.V.K.; funding acquisition, N.V.K. All authors have read and agreed to the published version of the manuscript.

Funding: This work has been supported by grants from the National Institutes of Health (NIGMS R35GM129294 to N.V.K.), the Welch Foundation (C-1930 to N.V.K.), and the Cystic Fibrosis Foundation (KANG19H0 to D.K. and KIRIEN20I0 to N.V.K.).

Institutional Review Board Statement: Not applicable.

Informed Consent Statement: Not Applicable.

Data Availability Statement: Data available upon request.

Conflicts of Interest: The authors declare no conflict of interest. The funders had no role in the design of the study; in the collection, analyses, or interpretation of data; in the writing of the manuscript, or in the decision to publish the results. 


\section{References}

1. Lyczak, J.B.; Cannon, C.L.; Pier, G.B. Lung infections associated with cystic fibrosis. Clin. Microbiol. Rev. 2002, 15, 194-222. [CrossRef] [PubMed]

2. Kollef, M.H.; Chastre, J.; Fagon, J.Y.; Francois, B.; Niederman, M.S.; Rello, J.; Torres, A.; Vincent, J.L.; Wunderink, R.G.; Go, K.W.; et al. Global prospective epidemiologic and surveillance study of ventilator-associated pneumonia due to Pseudomonas aeruginosa. Crit. Care Med. 2014, 42, 2178-2187. [CrossRef] [PubMed]

3. Saint-Criq, V.; Villeret, B.; Bastaert, F.; Kheir, S.; Hatton, A.; Cazes, A.; Xing, Z.; Sermet-Gaudelus, I.; Garcia-Verdugo, I.; Edelman, A.; et al. LasB protease impairs innate immunity in mice and humans by targeting a lung epithelial cystic fibrosis transmembrane regulator-IL-6-antimicrobial-repair pathway. Thorax 2018, 73, 49-61. [CrossRef] [PubMed]

4. Casilag, F.; Lorenz, A.; Krueger, J.; Klawonn, F.; Weiss, S.; Häussler, S. The LasB Elastase of Pseudomonas aeruginosa Acts in Concert with Alkaline Protease AprA To Prevent Flagellin-Mediated Immune Recognition. Infect. Immun. 2016, 84, 162-171. [CrossRef] [PubMed]

5. Minandri, F.; Imperi, F.; Frangipani, E.; Bonchi, C.; Visaggio, D.; Facchini, M.; Pasquali, P.; Bragonzi, A.; Visca, P. Role of Iron Uptake Systems in Pseudomonas aeruginosa Virulence and Airway Infection. Infect. Immun. 2016, 84, 2324-2335. [CrossRef]

6. Hauser, A.R. The type III secretion system of Pseudomonas aeruginosa: Infection by injection. Nat. Rev. Microbiol. 2009, 7, 654-665. [CrossRef]

7. Moradali, M.F.; Ghods, S.; Rehm, B.H. Pseudomonas aeruginosa Lifestyle: A Paradigm for Adaptation, Survival, and Persistence. Front. Cell Infect. Microbiol. 2017, 7, 39. [CrossRef]

8. Xiao, R.; Kisaalita, W.S. Iron acquisition from transferrin and lactoferrin by Pseudomonas aeruginosa pyoverdin. Microbiology 1997, 143 Pt 7, 2509-2515. [CrossRef]

9. Skaar, E.P. The battle for iron between bacterial pathogens and their vertebrate hosts. PLoS Pathog. 2010, 6, e1000949. [CrossRef]

10. Takase, H.; Nitanai, H.; Hoshino, K.; Otani, T. Impact of siderophore production on Pseudomonas aeruginosa infections in immunosuppressed mice. Infect. Immun. 2000, 68, 1834-1839. [CrossRef]

11. Ankenbauer, R.; Sriyosachati, S.; Cox, C.D. Effects of siderophores on the growth of Pseudomonas aeruginosa in human serum and transferrin. Infect. Immun. 1985, 49, 132-140. [CrossRef] [PubMed]

12. Banin, E.; Vasil, M.L.; Greenberg, E.P. Iron and Pseudomonas aeruginosa biofilm formation. Proc. Natl. Acad. Sci. USA 2005, 102, 11076-11081. [CrossRef] [PubMed]

13. Kang, D.; Kirienko, N.V. Interdependence between iron acquisition and biofilm formation in Pseudomonas aeruginosa. J. Microbiol. 2018, 56, 449-457. [CrossRef] [PubMed]

14. Lamont, I.L.; Beare, P.A.; Ochsner, U.; Vasil, A.I.; Vasil, M.L. Siderophore-mediated signaling regulates virulence factor production in Pseudomonasaeruginosa. Proc. Natl. Acad. Sci. USA 2002, 99, 7072-7077. [CrossRef] [PubMed]

15. Wilderman, P.J.; Vasil, A.I.; Johnson, Z.; Wilson, M.J.; Cunliffe, H.E.; Lamont, I.L.; Vasil, M.L. Characterization of an endoprotease (PrpL) encoded by a PvdS-regulated gene in Pseudomonas aeruginosa. Infect. Immun. 2001, 69, 5385-5394. [CrossRef] [PubMed]

16. Ochsner, U.A.; Johnson, Z.; Lamont, I.L.; Cunliffe, H.E.; Vasil, M.L. Exotoxin A production in Pseudomonas aeruginosa requires the iron-regulated pvdS gene encoding an alternative sigma factor. Mol. Microbiol. 1996, 21, 1019-1028. [CrossRef]

17. Jenkins, C.E.; Swiatoniowski, A.; Issekutz, A.C.; Lin, T.J. Pseudomonas aeruginosa exotoxin A induces human mast cell apoptosis by a caspase-8 and -3-dependent mechanism. J. Biol. Chem. 2004, 279, 37201-37207. [CrossRef]

18. Michalska, M.; Wolf, P. Pseudomonas Exotoxin A: Optimized by evolution for effective killing. Front. Microbiol. $2015,6,963$. [CrossRef]

19. McEwan, D.L.; Kirienko, N.V.; Ausubel, F.M. Host translational inhibition by Pseudomonas aeruginosa Exotoxin A Triggers an immune response in Caenorhabditis elegans. Cell Host Microbe 2012, 11, 364-374. [CrossRef]

20. Bradshaw, J.L.; Caballero, A.R.; Bierdeman, M.A.; Adams, K.V.; Pipkins, H.R.; Tang, A.; O'Callaghan, R.J.; McDaniel, L.S. Pseudomonas aeruginosa Protease IV Exacerbates Pneumococcal Pneumonia and Systemic Disease. mSphere 2018, 3. [CrossRef]

21. Malloy, J.L.; Veldhuizen, R.A.; Thibodeaux, B.A.; O'Callaghan, R.J.; Wright, J.R. Pseudomonas aeruginosa protease IV degrades surfactant proteins and inhibits surfactant host defense and biophysical functions. Am. J. Physiol. Lung Cell Mol. Physiol. 2005, 288, L409-L418. [CrossRef] [PubMed]

22. Guillon, A.; Brea, D.; Morello, E.; Tang, A.; Jouan, Y.; Ramphal, R.; Korkmaz, B.; Perez-Cruz, M.; Trottein, F.; O'Callaghan, R.J.; et al. Pseudomonas aeruginosa proteolytically alters the interleukin 22-dependent lung mucosal defense. Virulence 2017, 8, 810-820. [CrossRef] [PubMed]

23. Kirienko, N.V.; Kirienko, D.R.; Larkins-Ford, J.; Wahlby, C.; Ruvkun, G.; Ausubel, F.M. Pseudomonas aeruginosa disrupts Caenorhabditis elegans iron homeostasis, causing a hypoxic response and death. Cell Host Microbe 2013, 13, 406-416. [CrossRef] [PubMed]

24. Kang, D.; Kirienko, D.R.; Webster, P.; Fisher, A.L.; Kirienko, N.V. Pyoverdine, a siderophore from Pseudomonas aeruginosa, translocates into C. elegans, removes iron, and activates a distinct host response. Virulence 2018, 9, 804-817. [CrossRef] [PubMed]

25. Kirienko, N.V.; Ausubel, F.M.; Ruvkun, G. Mitophagy confers resistance to siderophore-mediated killing by Pseudomonas aeruginosa. Proc. Natl. Acad. Sci. USA 2015, 112, 1821-1826. [CrossRef] [PubMed]

26. Tjahjono, E.; Kirienko, N.V. A conserved mitochondrial surveillance pathway is required for defense against Pseudomonas aeruginosa. PLoS Genet. 2017, 13, e1006876. [CrossRef] 
27. Tjahjono, E.; McAnena, A.P.; Kirienko, N.V. The evolutionarily conserved ESRE stress response network is activated by ROS and mitochondrial damage. BMC Biol. 2020, 18, 74. [CrossRef]

28. Weigert, M.; Ross-Gillespie, A.; Leinweber, A.; Pessi, G.; Brown, S.P.; Kummerli, R. Manipulating virulence factor availability can have complex consequences for infections. Evol. Appl. 2017, 10, 91-101. [CrossRef]

29. Meyer, J.M.; Neely, A.; Stintzi, A.; Georges, C.; Holder, I.A. Pyoverdin is essential for virulence of Pseudomonas aeruginosa. Infect. Immun. 1996, 64, 518-523. [CrossRef]

30. Kirienko, D.R.; Revtovich, A.V.; Kirienko, N.V. A High-Content, Phenotypic Screen Identifies Fluorouridine as an Inhibitor of Pyoverdine Biosynthesis and Pseudomonas aeruginosa Virulence. mSphere 2016, 1. [CrossRef]

31. Kang, D.; Revtovich, A.V.; Chen, Q.; Shah, K.N.; Cannon, C.L.; Kirienko, N.V. Pyoverdine-Dependent Virulence of Pseudomonas aeruginosa Isolates from Cystic Fibrosis Patients. Front. Microbiol. 2019, 10, 2048. [CrossRef] [PubMed]

32. Imperi, F.; Massai, F.; Facchini, M.; Frangipani, E.; Visaggio, D.; Leoni, L.; Bragonzi, A.; Visca, P. Repurposing the antimycotic drug flucytosine for suppression of Pseudomonas aeruginosa pathogenicity. Proc. Natl. Acad. Sci. USA 2013, 110, 7458-7463. [CrossRef]

33. Costabile, G.; d'Angelo, I.; d'Emmanuele di Villa Bianca, R.; Mitidieri, E.; Pompili, B.; Del Porto, P.; Leoni, L.; Visca, P.; Miro, A.; Quaglia, F.; et al. Development of inhalable hyaluronan/mannitol composite dry powders for flucytosine repositioning in local therapy of lung infections. J. Control Release 2016, 238, 80-91. [CrossRef] [PubMed]

34. Ochsner, U.A.; Snyder, A.; Vasil, A.I.; Vasil, M.L. Effects of the twin-arginine translocase on secretion of virulence factors, stress response, and pathogenesis. Proc. Natl. Acad. Sci. USA 2002, 99, 8312-8317. [CrossRef] [PubMed]

35. Vasil, M.L.; Tomaras, A.P.; Pritchard, A.E. Identification and evaluation of twin-arginine translocase inhibitors. Antimicrob. Agents Chemother. 2012, 56, 6223-6234. [CrossRef]

36. Massai, F.; Saleeb, M.; Doruk, T.; Elofsson, M.; Forsberg, Å. Development, Optimization, and Validation of a High Throughput Screening Assay for Identification of Tat and Type II Secretion Inhibitors of Pseudomonas aeruginosa. Front. Cell Infect. Microbiol. 2019, 9, 250. [CrossRef]

37. Lee, J.H.; Kim, Y.G.; Cho, M.H.; Kim, J.A.; Lee, J. 7-fluoroindole as an antivirulence compound against Pseudomonas aeruginosa. FEMS Microbiol. Lett. 2012, 329, 36-44. [CrossRef]

38. Peppoloni, S.; Pericolini, E.; Colombari, B.; Pinetti, D.; Cermelli, C.; Fini, F.; Prati, F.; Caselli, E.; Blasi, E. The beta-Lactamase Inhibitor Boronic Acid Derivative SM23 as a New Anti-Pseudomonas aeruginosa Biofilm. Front. Microbiol. 2020, 11, 35. [CrossRef]

39. Zhou, J.W.; Luo, H.Z.; Jiang, H.; Jian, T.K.; Chen, Z.Q.; Jia, A.Q. Hordenine: A Novel Quorum Sensing Inhibitor and Antibiofilm Agent against Pseudomonas aeruginosa. J. Agric. Food Chem. 2018, 66, 1620-1628. [CrossRef]

40. Kang, D.; Kirienko, N.V. High-Throughput Genetic Screen Reveals that Early Attachment and Biofilm Formation Are Necessary for Full Pyoverdine Production by Pseudomonas aeruginosa. Front. Microbiol. 2017, 8, 1707. [CrossRef]

41. Braud, A.; Hoegy, F.; Jezequel, K.; Lebeau, T.; Schalk, I.J. New insights into the metal specificity of the Pseudomonas aeruginosa pyoverdine-iron uptake pathway. Environ. Microbiol. 2009, 11, 1079-1091. [CrossRef] [PubMed]

42. Ross-Gillespie, A.; Weigert, M.; Brown, S.P.; Kummerli, R. Gallium-mediated siderophore quenching as an evolutionarily robust antibacterial treatment. Evol. Med. Public Health 2014, 2014, 18-29. [CrossRef] [PubMed]

43. Wang, X.; Kleerekoper, Q.; Revtovich, A.V.; Kang, D.; Kirienko, N.V. Identification and validation of a novel anti-virulent that binds to pyoverdine and inhibits its function. Virulence 2020, 11, 1293-1309. [CrossRef] [PubMed]

44. Kirienko, D.R.; Kang, D.; Kirienko, N.V. Novel Pyoverdine Inhibitors Mitigate Pseudomonas aeruginosa Pathogenesis. Front. Microbiol. 2019, 9, 3317. [CrossRef] [PubMed]

45. Mahajan-Miklos, S.; Tan, M.W.; Rahme, L.G.; Ausubel, F.M. Molecular mechanisms of bacterial virulence elucidated using a Pseudomonas aeruginosa-Caenorhabditis elegans pathogenesis model. Cell 1999, 96, 47-56. [CrossRef]

46. Usher, L.R.; Lawson, R.A.; Geary, I.; Taylor, C.J.; Bingle, C.D.; Taylor, G.W.; Whyte, M.K. Induction of neutrophil apoptosis by the Pseudomonas aeruginosa exotoxin pyocyanin: A potential mechanism of persistent infection. J. Immunol. 2002, 168, 1861-1868. [CrossRef]

47. Eraso, A.J.; Albesa, I. Potential Toxicity of Pyoverdin From Pseudomonas on Mouse Liver. J. Food Process. Preserv. 1996, $20,12$. [CrossRef]

48. Folschweiller, N.; Gallay, J.; Vincent, M.; Abdallah, M.A.; Pattus, F.; Schalk, I.J. The interaction between pyoverdin and its outer membrane receptor in Pseudomonas aeruginosa leads to different conformers: A time-resolved fluorescence study. Biochemistry 2002, 41, 14591-14601. [CrossRef]

49. Oliver, J.M.; Berlin, R.D.; Davis, B.H. Use of horseradish peroxidase and fluorescent dextrans to study fluid pinocytosis in leukocytes. Methods Enzymol. 1984, 108, 336-347. [CrossRef]

50. Lee, D.G.; Urbach, J.M.; Wu, G.; Liberati, N.T.; Feinbaum, R.L.; Miyata, S.; Diggins, L.T.; He, J.; Saucier, M.; Déziel, E.; et al. Genomic analysis reveals that Pseudomonas aeruginosa virulence is combinatorial. Genome Biol. 2006, 7, R90. [CrossRef]

51. Visca, P.; Imperi, F.; Lamont, I.L. Pyoverdine siderophores: From biogenesis to biosignificance. Trends Microbiol. 2007, 15, 22-30. [CrossRef] [PubMed]

52. Aiello, D.; Williams, J.D.; Majgier-Baranowska, H.; Patel, I.; Peet, N.P.; Huang, J.; Lory, S.; Bowlin, T.L.; Moir, D.T. Discovery and characterization of inhibitors of Pseudomonas aeruginosa type III secretion. Antimicrob. Agents Chemother. 2010, 54, 1988-1999. [CrossRef] [PubMed] 
53. Starkey, M.; Lepine, F.; Maura, D.; Bandyopadhaya, A.; Lesic, B.; He, J.; Kitao, T.; Righi, V.; Milot, S.; Tzika, A.; et al. Identification of anti-virulence compounds that disrupt quorum-sensing regulated acute and persistent pathogenicity. PLoS Pathog. 2014, 10, e1004321. [CrossRef]

54. Zhu, J.; Cai, X.; Harris, T.L.; Gooyit, M.; Wood, M.; Lardy, M.; Janda, K.D. Disarming Pseudomonas aeruginosa virulence factor LasB by leveraging a Caenorhabditis elegans infection model. Chem. Biol. 2015, 22, 483-491. [CrossRef] [PubMed]

55. Kany, A.M.; Sikandar, A.; Haupenthal, J.; Yahiaoui, S.; Maurer, C.K.; Proschak, E.; Köhnke, J.; Hartmann, R.W. Binding Mode Characterization and Early in Vivo Evaluation of Fragment-Like Thiols as Inhibitors of the Virulence Factor LasB from Pseudomonas aeruginosa. ACS Infect. Dis. 2018, 4, 988-997. [CrossRef]

56. Moy, T.I.; Conery, A.L.; Larkins-Ford, J.; Wu, G.; Mazitschek, R.; Casadei, G.; Lewis, K.; Carpenter, A.E.; Ausubel, F.M. Highthroughput screen for novel antimicrobials using a whole animal infection model. ACS Chem. Biol. 2009, 4, 527-533. [CrossRef]

57. Breger, J.; Fuchs, B.B.; Aperis, G.; Moy, T.I.; Ausubel, F.M.; Mylonakis, E. Antifungal chemical compounds identified using a C. elegans pathogenicity assay. PLoS Pathog. 2007, 3, e18. [CrossRef]

58. Kim, W.; Zhu, W.; Hendricks, G.L.; Van Tyne, D.; Steele, A.D.; Keohane, C.E.; Fricke, N.; Conery, A.L.; Shen, S.; Pan, W.; et al. A new class of synthetic retinoid antibiotics effective against bacterial persisters. Nature 2018, 556, 103-107. [CrossRef]

59. Wareham, D.W.; Papakonstantinopoulou, A.; Curtis, M.A. The Pseudomonas aeruginosa PA14 type III secretion system is expressed but not essential to virulence in the Caenorhabditis elegans-P. aeruginosa pathogenicity model. FEMS Microbiol. Lett. 2005, 242, 209-216. [CrossRef]

60. Woodworth, B.A.; Tamashiro, E.; Bhargave, G.; Cohen, N.A.; Palmer, J.N. An in vitro model of Pseudomonas aeruginosa biofilms on viable airway epithelial cell monolayers. Am. J. Rhinol. 2008, 22, 235-238. [CrossRef]

61. Carterson, A.J.; Honer zu Bentrup, K.; Ott, C.M.; Clarke, M.S.; Pierson, D.L.; Vanderburg, C.R.; Buchanan, K.L.; Nickerson, C.A.; Schurr, M.J. A549 lung epithelial cells grown as three-dimensional aggregates: Alternative tissue culture model for Pseudomonas aeruginosa pathogenesis. Infect. Immun. 2005, 73, 1129-1140. [CrossRef]

62. Sato, H.; Frank, D.W. ExoU is a potent intracellular phospholipase. Mol. Microbiol. 2004, 53, 1279-1290. [CrossRef]

63. Shafikhani, S.H.; Morales, C.; Engel, J. The Pseudomonas aeruginosa type III secreted toxin ExoT is necessary and sufficient to induce apoptosis in epithelial cells. Cell Microbiol. 2008, 10, 994-1007. [CrossRef] [PubMed]

64. Sutterwala, F.S.; Mijares, L.A.; Li, L.; Ogura, Y.; Kazmierczak, B.I.; Flavell, R.A. Immune recognition of Pseudomonas aeruginosa mediated by the IPAF/NLRC4 inflammasome. J. Exp. Med. 2007, 204, 3235-3245. [CrossRef]

65. Miao, E.A.; Ernst, R.K.; Dors, M.; Mao, D.P.; Aderem, A. Pseudomonas aeruginosa activates caspase 1 through Ipaf. Proc. Natl. Acad. Sci. USA 2008, 105, 2562-2567. [CrossRef] [PubMed]

66. Franchi, L.; Stoolman, J.; Kanneganti, T.D.; Verma, A.; Ramphal, R.; Nunez, G. Critical role for Ipaf in Pseudomonas aeruginosainduced caspase-1 activation. Eur. J. Immunol. 2007, 37, 3030-3039. [CrossRef] [PubMed]

67. Deng, Q.; Wang, Y.; Zhang, Y.; Li, M.; Li, D.; Huang, X.; Wu, Y.; Pu, J.; Wu, M. Pseudomonas aeruginosa Triggers Macrophage Autophagy to Escape Intracellular Killing by Activation of the NLRP3 Inflammasome. Infect. Immun. 2016, 84, 56-66. [CrossRef] [PubMed]

68. Golovkine, G.; Faudry, E.; Bouillot, S.; Voulhoux, R.; Attree, I.; Huber, P. VE-cadherin cleavage by LasB protease from Pseudomonas aeruginosa facilitates type III secretion system toxicity in endothelial cells. PLoS Pathog. 2014, 10, e1003939. [CrossRef] [PubMed]

69. Huber, P.; Bouillot, S.; Elsen, S.; Attree, I. Sequential inactivation of Rho GTPases and Lim kinase by Pseudomonas aeruginosa toxins ExoS and ExoT leads to endothelial monolayer breakdown. Cell Mol. Life Sci. 2014, 71, 1927-1941. [CrossRef] [PubMed]

70. Pukatzki, S.; Kessin, R.H.; Mekalanos, J.J. The human pathogen Pseudomonas aeruginosa utilizes conserved virulence pathways to infect the social amoeba Dictyostelium discoideum. Proc. Natl. Acad. Sci. USA 2002, 99, 3159-3164. [CrossRef]

71. Leong, W.; Lutz, C.; Williams, J.; Poh, Y.H.; Yee, B.Y.K.; Chua, C.; Rice, S.A.; Givskov, M.; Sanderson-Smith, M.; McDougald, D. Pseudomonas aeruginosa isolates co-incubated with Acanthamoeba castellanii exhibit phenotypes similar to chronic cystic fibrosis isolates. bioRxiv 2020. [CrossRef]

72. Conery, A.L.; Larkins-Ford, J.; Ausubel, F.M.; Kirienko, N.V. High-throughput screening for novel anti-infectives using a C. elegans pathogenesis model. Curr. Protoc. Chem. Biol. 2014, 6, 25-37. [CrossRef] [PubMed]

73. Anderson, Q.L.; Revtovich, A.V.; Kirienko, N.V. A High-throughput, High-content, Liquid-based C. elegans Pathosystem. J. Vis. Exp. 2018, 137, e58068. [CrossRef] [PubMed] 